\title{
Usual dietary salt intake and asthma in children: a case-control study
}

\author{
Kitaw Demissie, Pierre Ernst, Katherine Gray Donald, Lawrence Joseph
}

\begin{abstract}
Background - A decline in host resistance due to an alteration in diet - primarily of salt - was recently put forward as a possible explanation for rising rates of asthma.

Methods - A case-control study was coducted in participants in a prevalence survey which included 187 children with asthma (defined by prior diagnosis and/or a decline in forced expiratory volume in one second $\left(\mathrm{FEV}_{1}\right)$ of $\geqslant 10 \%$ after exercise) and 145 age and sex matched controls. Subjects were selected from 989 children aged 5-13 years attending 18 elementary schools on the island of Montreal. Usual dietary salt intake was estimated from a food frequency questionnaire administered to the mother, and a salt intake score was used to group the children into quartiles from I (lowest) to IV (highest salt intake). Bronchial hyperresponsiveness to methacholine was assessed by Yan's method. Cases and controls were combined in one group to examine the relationship of salt intake to bronchial hyperresponsiveness to methacholine. Methacholine responsiveness was expressed as a dose-response slope and ranks of dose-response slopes were used in the analysis.
\end{abstract}

Results - After accounting for important confounding variables, there was no association between asthma and salt intake, while methacholine dose-response slope ranks increased with increasing salt intake and methacholine responsiveness was greater in the highest quartile than in the lowest quartile of salt intake. The median dose-response slopes in \% fall in $\mathrm{FEV}_{1}$ per $\mu$ mol methacholine for quartiles I, II, III, and IV were $5 \cdot 4,5 \cdot 9,7 \cdot 7$, and $8 \cdot 7$.

Conclusions - No association was found between asthma or exercise-induced bronchospasm and dietary salt intake. Bronchial hyperresponsiveness to methacholine did, however, appear to increase with greater salt intake, but the relevance of this association to asthma is unclear.

(Thorax 1996;51:59-63)

Keywords: salt intake, bronchial hyperresponsiveness, children.

Asthma morbidity and mortality is greater in communities adopting a more western lifestyle and in migrants as they move from rural underdeveloped to urban westernised areas. ${ }^{1-4}$ The lack of an adequate epidemiological explanation for this phenomenon, coupled with the increase in salt consumption with urbanisation, led Burney ${ }^{2}$ to hypothesise that increased sodium intake might be partly responsible for the increased mortality and morbidity due to asthma. He tested the hypothesis using regional data from England and Wales and found a strong correlation between table salt purchases and asthma mortality in men and children of both sexes, but not in women. Two controlled crossover trials ${ }^{56}$ have recently found increasing dietary salt intake to result in worsening asthma symptoms and an increase in bronchodilator consumption. The degree to which such salt loading might be applicable to salt consumption observed in uncontrolled situations is unclear.

In contrast, Lieberman and $\mathrm{Heimer}^{7}$ in a non-blinded randomised crossover trial involving 17 asthmatic patients found no significant difference in peak flows or peak flow variability between periods of low and high salt intake. Pistelli et $a l^{8}$ conducted a community based cross sectional study in children aged 9-16 years and found the reported use of table salt to be strongly related to respiratory symptoms suggestive of asthma in boys, but not in girls. These discrepancies in the reported results of the different investigations and the limited data arising from community based studies of children ${ }^{9}$ led us to examine the relationship of normal dietary salt intake to asthma in children.

\section{Methods}

A case-control study among participants in a cross sectional survey was conducted in the city of Montreal, Canada from April 1990 to November 1992. Eighteen schools were selected on the island of Montreal in order to represent a broad range of socioeconomic status. One class from each school from each of grades 1 (age 5-7 years), 3 (age 8 and 9 years), and 5 (age 10-13 years) was selected. A questionnaire on history of asthma diagnosed by a doctor, respiratory symptoms and illnesses, asthma in a parent, exposure to second-hand tobacco smoke, housing conditions including the current presence of pets, and a letter of consent were completed by parents.

In the school gymnasium each subject's age, sex, height, and weight were recorded and spirometric tests were carried out sitting and with nose clips using two Collins 10 litre water- 
sealed spirometers (Warren E Collins, Braintree, Massachusetts, USA) according to current American Thoracic Society guidelines, ${ }^{10}$ and the best $\mathrm{FEV}_{1}$ from any flow-volume curve, both at baseline and after exercise, was used for analysis. ${ }^{11}$ Following five minutes of inactivity, heart rate was measured using a digital plethysmograph (Heart Rate Inc, Costa Mesa, California, USA). Children then ran around the gymnasium for six minutes at a pace judged sufficient to attain $\geqslant 90 \%$ of the predicted maximal heart rate ${ }^{12} ;$ heart rate was remeasured immediately on completion of exercise. Five and 10 minutes after completion of exercise the spirometric tests were repeated on the same spirometer. Average room temperature and relative humidity, as well as percentage maximum heart rate attained, were similar among children who did and did not demonstrate $a \geqslant 10 \%$ fall in $\mathrm{FEV}_{1}$ after exercise (exercise-induced bronchospasm). Subjects did not take part in the exercise test if they were excused from gym class or if their $\mathrm{FEV}_{1}$ was below $70 \%$ predicted. No specific instructions were given concerning the use of medications including those for asthma. The exercise test was completed successfully in 989 children. Only $11(1 \cdot 11 \%)$ had been dispensed a bronchodilator (for example, $\beta$ agonist) at the time of the test.

The subjects for the case-control study were selected from the participants in the cross sectional survey. A case was defined by the presence of either (1) a history of asthma as reported by parents, or (2) a fall in $\mathrm{FEV}_{1}$ of $\geqslant 10 \%$ after exercise. ${ }^{13}$ The next child on the alphabetical class list of the same sex as the case, but without either of these criteria for asthma, was chosen as a control. If the parents of the case refused further participation, both this child and the one chosen to serve as a control were not studied further, while if a child chosen as a control (that is, without asthma or exerciseinduced bronchospasm) refused, the next appropriate child on the class list was selected. For 38 cases a comparison child could not be obtained.

A food frequency questionnaire designed specifically to assess the normal intake of salt in the diet of the child was administered to a parent (almost always the mother). Food items high in sodium ${ }^{14}$ that are frequently consumed were grouped into nine food groupings; portion sizes were not indicated. Parents were also asked about their child's preference for salty foods. Parents chose from four frequency categories for each of the nine food groups their child might consume, and a score was obtained from the sum of the items multiplied by the frequency of each item (maximum value 27). The salt preference score obtained by asking the question: "Does your child like salty foods?" (very much, 2; somewhat, 1 ; not at all, 0 ) was then added to obtain the overall salt intake score (maximum value 29). The questionnaire is provided in the appendix. Food frequency is widely used as the dietary method of choice to provide an approximate ranking of the normal intake of individuals on a specific dietary component. ${ }^{15}$ In measuring salt intake, such an estimate of usual intake is particularly important because of the high day-to-day variability in intake. ${ }^{16}$

The last occupation of the parents was transformed into the corresponding codes of the Canadian Classification and Dictionary of Occupations. ${ }^{17}$ These codes were then converted into socioeconomic status scores for the child based on income and education level for each occupation from the tables developed by Blishen and colleagues. ${ }^{18}$ The highest score from either parent was retained for analysis.

In order to investigate in detail the risk factors for bronchial hyperresponsiveness, methacholine bronchoprovocation and allergy skin tests were performed on cases and controls at home in the evening. All children with an $\mathrm{FEV}_{1}$ of $>75 \%$ of their forced vital capacity had a methacholine challenge test using the method of Yan. ${ }^{19} \mathrm{~A}$ long protocol with nine incremental doses was followed among the cases, with six incremental doses given to the controls. The test began with three inhalations of $0.9 \%$ saline with $\mathrm{FEV}_{1}$ being measured one minute later. Provided that the $\mathrm{FEV}_{1}$ did not fall by more than $10 \%$ of the baseline value, methacholine solutions were administered according to the following cumulative doses in $\mu \mathrm{mol}: 0.030$, $0.060,0.124,0.244,0.499,0.996,1.990$, 3.913 , and 7.80 for the long protocol and $0.030,0.094,0.477,1.967,3.89$, and 7.78 for the short protocol. At each dose level subjects performed inspiratory capacity inhalation with a five second breath hold while seated and wearing nose clips. A forced expiratory manoeuvre was performed 60 seconds after each dose. The challenge was stopped when the $\mathrm{FEV}_{1}$ had fallen by $20 \%$ or more, or the final dose had been reached.

Solutions for allergen skin testing comprised histamine $(1 \mathrm{mg} / \mathrm{ml})$, normal saline, Dermatophagoides pteronyssinus, Dermatophagoides farinae, mixed grass pollens, tree pollens, ragweed, mixed moulds, Aspergillus sp, cat epithelium, and cockroach antigen. Needles (26 gauge) were used to break the skin. The resultant weal diameters were measured at right angles using Vernier callipers at 10 and 15 minutes. A weal of $\geqslant 3 \mathrm{~mm}$ was taken as a positive response. If there was no positive response to histamine, skin testing was regarded as invalid.

The study was approved by the ethics committee of McGill University.

\section{DATA ANALYSIS}

The salt intake score was used to group the children into quartiles (quartile I with the lowest and quartile IV with the highest salt score, respectively). The relationship between asthma and salt intake was examined using a logistic regression model $^{20}$ before and after adjusting for potential confounding variables. Statistical significance of the regression coefficients was determined by the $\chi^{2}$ approximation to the likelihood ratio statistic.

Cases and controls were combined into one group in order to investigate the relationship of salt intake to bronchial hyperresponsiveness to methacholine. For the methacholine broncho- 
Table 1 Descriptive characteristics of the subsample selected for further study at home

\begin{tabular}{|c|c|c|c|c|}
\hline & \multicolumn{2}{|l|}{ Cases } & \multicolumn{2}{|l|}{ Controls } \\
\hline & $\begin{array}{l}\text { Participants } \\
(n=187)\end{array}$ & $\begin{array}{l}\text { Non-participants } \\
(n=82)\end{array}$ & $\begin{array}{l}\text { Participants } \\
(n=145)\end{array}$ & $\begin{array}{l}\text { Non-participants } \\
(n=86)\end{array}$ \\
\hline $\begin{array}{l}\text { Boys (\%) } \\
\text { Caucasians (\%) } \\
\text { Mother smokes (\%) } \\
\text { Father smokes (\%) } \\
\text { Smoked while pregnant (\%) } \\
\text { History of asthma (\%) } \\
\text { Other respiratory history* (\%) }\end{array}$ & $\begin{array}{l}55 \cdot 4 \\
74 \cdot 6 \\
37 \cdot 3 \\
43 \cdot 5 \\
29 \cdot 6 \\
44 \cdot 9 \\
47 \cdot 1\end{array}$ & $\begin{array}{l}53 \cdot 2 \\
86 \cdot 1 \\
45 \cdot 2 \\
50 \cdot 8 \\
43 \cdot 1 \\
37 \cdot 2 \\
58 \cdot 9\end{array}$ & $\begin{array}{l}52 \cdot 5 \\
82 \cdot 0 \\
43 \cdot 2 \\
50 \cdot 5 \\
33 \cdot 9 \\
\text { NA } \\
33 \cdot 1\end{array}$ & $\begin{array}{l}58 \cdot 5 \\
83 \cdot 3 \\
46 \cdot 3 \\
56 \cdot 1 \\
32 \cdot 9 \\
\mathrm{NA} \\
41 \cdot 1\end{array}$ \\
\hline
\end{tabular}

* History of either pneumonia, bronchiolitis, whooping cough, or croup.

$\mathrm{NA}=$ not applicable.

provocation test the dose-response data of each child were summarised according to the method of O'Connor et $\mathrm{al}^{21}$ - that is, percentage decline in $\mathrm{FEV}_{1} /$ dose - where percentage decline in $\mathrm{FEV}_{1}$ was defined as the decline in $\mathrm{FEV}_{1}$ (from the post saline value) after the final methacholine dose, and dose was defined as the final cumulative methacholine dose administered. This method of expressing methacholine responsiveness in population studies has been validated by several groups. ${ }^{223}$ The dose-response slope was ranked because of the non-normal distribution which persisted, despite various transformations. The ranks were used as an outcome variable for subsequent multivariate linear regression analysis where approximate normality was observed in the residuals.

Statistical analysis was carried out using SAS and EGRET statistical softwares. ${ }^{2425}$

\section{Results}

A total of 1274 children were eligible to participate in the cross sectional survey from 18 Montreal schools selected. Of these, the parents of 130 children $(10 \cdot 2 \%)$ refused participation for their children, while a further 75 children $(5.9 \%)$ did not return the questionnaire and consent form. There were no meaningful differences between participants and non-participants as to the age of the child (mean (SD) $8.8(1.8)$ versus $8 \cdot 0(1.9)$ ), sex (boys: $51 \%$ versus $55 \%$ ), race (Caucasians: $78 \%$ versus $81 \%$ ), socioeconomic status assessed by neighbourhood census data (poorest socioeconomic status quartile: $27 \%$ versus $23 \%$ ). Spirometric tests were not performed for a further 23 children because of illness or absence from school. Of the 1046 children who attempted spirometric testing, $28(2 \cdot 7 \%)$ were unable to complete the test successfully and such failure was more common among younger children but was unrelated to reported respiratory illness, symptoms, or socioeconomic status. The spirometric data of a further 28 children $(2 \cdot 7 \%)$ were lost after the test. One child $(0 \cdot 1 \%)$ was excluded because of a severe attack of asthma at the time of the test.

Of the 989 children $(77 \cdot 6 \%)$ who participated in the cross sectional survey and had spirometric data, 269 children $(27 \cdot 2 \%)$ met the case definition and for 231 of these cases a child of the same sex in the same class was available to serve as a control. Of the 269 children with either exercise-induced bronchospasm or a history of asthma (80 of whom had a history of asthma alone), $187(70 \%)$ were visited at home. Of the 231 children without exercise-induced bronchospasm or a history of asthma, 145 (63\%) were visited. Among the cases (table 1), non-participants were more likely to be Caucasian, have mothers or fathers who currently smoke, or mothers who had smoked during pregnancy. Asthma, but not a history of other respiratory illness, was more common among participants, indicating an increased interest in the study by parents of children with this common childhood disorder despite the fact that our study was presented as an inquiry into respiratory health in general. Among the control group differences between participants and non-participants were less pronounced, although they were mostly in a similar direction to the cases.

The prevalences of wheeze, allergy skin test positivity, and bronchial hyperresponsiveness to methacholine were higher among the cases than the controls, while pre-exercise lung function levels were lower (table 2).

Table 3 presents the relationship of usual dietary salt intake to childhood asthma (defined by a history of asthma and/or a decline in $\mathrm{FEV}_{1}$ of $\geqslant 10 \%$ after exercise). Usual dietary salt intake was not found to be associated with asthma in children when examined crudely or after adjusting for the effects of age, sex, race, asthma in a parent, socioeconomic status, and prenatal and postnatal exposure to tobacco smoke. The inequality of cells in the quartiles resulted from ties in the values of the salt score.

Table 2 Indicators of asthma among the cases and controls

\begin{tabular}{lcc}
\hline & $\begin{array}{l}\text { Cases } \\
(n=187)\end{array}$ & $\begin{array}{c}\text { Controls } \\
(n=145)\end{array}$ \\
\hline Ever wheeze (\%) & $49 \cdot 2$ & $19 \cdot 7$ \\
Allergy skin test positivity (\%)** & 43.7 & 31.4 \\
Asthma in a parent (\%) & 18.5 & 6.0 \\
Methacholine responsive (\%) $\dagger_{\text {FEV }} \neq$ & 31.0 & $19 \cdot 4$ \\
FEV & -1.50 & +1.54 \\
\hline
\end{tabular}

$\mathrm{FEV}_{1}=$ forced expiratory volume in one second; $\mathrm{FVC}=$ forced vital capacity.

$* 3 \mathrm{~mm}$ weal to one or more of the nine aeroallergens tested (see text for explanation).

+ Children with $\geqslant 20 \%$ fall in $\mathrm{FEV}_{1}$ after $\leqslant 7.8 \mu \mathrm{mol}$ methacholine.

$\neq \mathrm{FEV}_{1}$ and $\mathrm{FEV}_{1} / \mathrm{FVC}$ were expressed as change from $100 \%$ in ratio of observed to expected value and are adjusted for sex race, the natural logarithm (ln) of height, $\ln$ of age, and $\ln$ of body mass index. 
Table 3 Unadjusted and adjusted odds ratios (with 95\% confidence intervals) for the association of salt intake with asthma $\dagger$

\begin{tabular}{llll}
\hline Salt score quartiles* & $n$ & Unadjusted odds ratio & Adjusted odds ratio \\
\hline I & 76 & Reference category & Reference category \\
II & 79 & $0.90(0.48$ to $1 \cdot 70)$ & $1 \cdot 07(0.51$ to $2 \cdot 27)$ \\
III & 82 & $0.90(0.48$ to $1 \cdot 69)$ & $0.81(0.37$ to $1 \cdot 78)$ \\
IV & 95 & $0.89(0.49$ to $1 \cdot 62)$ & $1 \cdot 12(0.54$ to $2 \cdot 33)$ \\
\hline
\end{tabular}

* Salt intake increases from quartile I to IV (see text for explanation).

† Asthma is defined as a $\geqslant 10 \%$ decline in $\mathrm{FEV}_{1}$ after exercise and/or a history of diagnosed t Asthma.

$¥$ Adjusted for age, sex, race, asthma in a parent, socioeconomic status, and prenatal and postnatal exposure to tobacco smoke.
Table 4 Relationship of dietary salt intake to methacholine dose-response slope (DRS)

\begin{tabular}{lll}
\hline $\begin{array}{l}\text { Salt score } \\
\text { quartilest }\end{array}$ & $\begin{array}{l}\text { DRS rank coefficient } \\
(95 \% \mathrm{CI}) \ddagger\end{array}$ & $\begin{array}{l}\text { Median } \mathrm{DRS} \\
(\% \text { per } \mu \mathrm{mol})\end{array}$ \\
\hline I & Reference category & $5 \cdot 4$ \\
II & $5 \cdot 7(-24 \cdot 9$ to $36 \cdot 3)$ & $5 \cdot 9$ \\
III & $28 \cdot 4(-2 \cdot 8$ to $59 \cdot 7)$ & $7 \cdot 7$ \\
IV & $34 \cdot 2(4.2$ to $64 \cdot 2)$ & $8 \cdot 7$ \\
\hline
\end{tabular}

$95 \% \mathrm{CI}=95 \%$ confidence interval.

† Salt intake increases from quartile I to IV (see text for explanation).

$\neq$ poefficient is adjusted for age, sex, race, parental asthma, $\mp$ Coefficient is adjusted for age, sex, race, parental asthma,
socioeconomic status, and prenatal and postnatal exposure to tobacco smoke.

We also investigated the relationship between usual dietary salt intake and bronchial hyperresponsiveness to methacholine by combining both cases and controls into a single group. Table 4 shows the relationship of methacholine dose response to dietary salt intake after accounting for the effects of potential confounding variables. The ranks for dose-response slope increase with increasing salt intake and are significantly different between the highest and lowest quartiles. To illustrate this, median dose-response slopes are calculated within each quartile of salt intake. There were no significant differences in these relationships according to sex, allergy skin test positivity, or race (non-significant interaction terms).

\section{Discussion}

We were unable to show any association between usual salt intake and diagnosed asthma or exercise-induced bronchospasm using a casecontrol design. When considering cases and controls as a single group, however, we found bronchial hyperresponsiveness to methacholine to increase with usual dietary salt intake. This discrepancy could be due to the different pathophysiological mechanisms underlying exercise and methacholine airway challenges. ${ }^{26}$

The measure of salt intake used in this study has not been validated because of the difficulty in collecting multiple 24 hour urine samples in a large number of children. The dietary method most appropriate for measuring usual dietary intake of a single nutrient is a food frequency questionnaire ${ }^{14}$ Food frequency questionnaires for other nutrients have been used widely and found to relate well to more detailed methods of dietary evaluation. ${ }^{14}$ Misclassification of children for salt intake is likely, however, and might have resulted in the attenuation of the association between salt and asthma among our study subjects.

Since children were more likely to have been included in the subsample studied if they had a history of asthma or demonstrated exerciseinduced bronchoconstriction, and because such traits are related to methacholine responsiveness, a spurious correlation between methacholine responsiveness could have been created if a history of asthma or exerciseinduced bronchospasm were related to salt intake. This was not the case, however. To be sure such confounding was not present, the relation between methacholine responsiveness and salt intake was re-examined after adjusting for the occurrence of exercise-induced bronchospasm or a history of asthma and the relationship was unchanged.

The fact that more children of smoking mothers did not participate in the study could have attenuated the association between usual salt intake and asthma. This is because smoking is more prevalent in mothers with low socioeconomic status and it is possible that socioeconomic status and salt intake are related. ${ }^{27}$ At the same time, exposure to environmental tobacco smoke and airways responsiveness may be related. ${ }^{28}$ Thus, non-participation of smoking mothers will result in the preferential exclusion of children with a high intake of salt and with airways hyperresponsiveness. However, socioeconomic status and usual dietary salt intake were not found to be related in our dataset.

The biological mechanisms that might explain the role of dietary salt intake in airways responsiveness remain uncertain. As summarised by Burney, ${ }^{2}$ the added dietary sodium load might increase the contribution of the electrogenic $\mathrm{Na}^{+}$pump to the resting membrane potential and potentiate the hyperpolarisation of the bronchial muscle cells. A common aetiological role of dietary sodium to both asthma and hypertension is also suggested. $^{2}$ Bronchial hyperresponsiveness has been linked to increased $\mathrm{Na}^{+} / \mathrm{K}^{+}$ATPase activity in animal models, ${ }^{29-31}$ as well as to increased extracellular $\mathrm{K}^{+}$and smooth muscle contraction. ${ }^{32-34}$ The control of potassium homeostasis is through the adrenergic system and this control is impaired in asthmatic subjects. ${ }^{35}$ This might explain the previously reported relationship observed between urinary potassium excretion and bronchial hyperresponsiveness. ${ }^{35}$

In conclusion, we found dietary salt intake to be related to bronchial hyperresponsiveness to methacholine, but not to childhood asthma, as determined by a history of asthma and/or a decline in $\mathrm{FEV}_{1}$ by $\geqslant 10 \%$ after exercise. Our results further underline the conclusions of previous studies ${ }^{36}$ that the study of risk factors for asthma in community based studies may be substantially affected by the measure of asthma chosen, and that measures of nonspecific bronchial responsiveness may be less helpful than initially hoped. 


\section{Appendix}

FOOD FREQUENCY QUESTIONNAIRE

Below is a list of foods your child may eat. Please indicate how often your child eats each of the foods.

\begin{tabular}{|c|c|c|c|c|}
\hline & $\begin{array}{l}\text { Most } \\
\text { days }\end{array}$ & $\begin{array}{l}3-5 \\
\text { times } \\
\text { per week }\end{array}$ & $\begin{array}{l}1-2 \\
\text { times } \\
\text { per week }\end{array}$ & $\begin{array}{l}\text { Less than } \\
\text { once } \\
\text { per week }\end{array}$ \\
\hline \multicolumn{5}{|l|}{ Cheese slices } \\
\hline \multicolumn{5}{|l|}{$\begin{array}{l}\text { Bacon or salami or } \\
\text { bologna, etc }\end{array}$} \\
\hline \multicolumn{5}{|l|}{$\begin{array}{l}\text { Potato chips, peanuts, } \\
\text { pretzels, corn chips, } \\
\text { etc }\end{array}$} \\
\hline \multicolumn{5}{|l|}{ Salted crackers } \\
\hline \multicolumn{5}{|l|}{$\begin{array}{l}\text { Canned or packaged } \\
\text { soup }\end{array}$} \\
\hline \multicolumn{5}{|l|}{ Kraft dinner, lasagna } \\
\hline \multicolumn{5}{|l|}{$\begin{array}{l}\text { Frozen TV dinners, } \\
\text { pot pies, etc }\end{array}$} \\
\hline \multicolumn{5}{|l|}{ Dill pickles } \\
\hline Ketchup, soy sauce & & & & \\
\hline
\end{tabular}

Do you like salty foods?

Very much

Somewhat

Not at all

Do you usually add salt to foods?

\section{Yes \\ No}

The authors acknowledge the advice of Professors Margaret Becklake and Ben Armstrong

This study was supported by the Medical Reseach Council of Canada and the Respiratory Health Network of Centres of Excellence (Canada). PE is Senior Chercheur Boursier, Fonds de la Recherche en Santé du Quebec.

1 Charlton JRH, Hartley RM, Silver R, Holland WW. Geographical variation in mortality from conditions amenable to medical intervention in England and Wales. Lance 1983;i:691-6.

2 Burney PFJ. A diet rich in sodium may potentiate asthma, epidemiological evidence for a new hypothesis. Chest 1987 ; 91(Suppl):143-8S

3 Van Niekerk CH, Weinberg EG, Shore SC, Heere HDEV, Van Schalkwyk DJ. Prevalence of asthma, a comparative study of urban and rural Xhosa children. Clin Allergy study of urban

4 Waite DA, Eyles EF, Tonkin SL, O'Donnell TV. Asthma prevalence in Tokelauan children in two environments. Clin Allergy 1980;10:71-5.

5 Medici TC, Schmid AZ, Häcki M, Vetter W. Are asthmatics salt-sensitive? A preliminary controlled study. Chest 1993 104:1138-43.

6 Carey OJ, Locke C, Cookson JB. Effect of alterations of dietary sodium on the severity of asthma in men. Thorax 1993;48:714-8.

7 Lieberman D, Heimer D. Effect of dietary sodium on the severity of bronchial asthma. Thorax 1992;47:360-2.

8 Pistelli R, Forastiere F, Corbo GM, Dell'Orco V, Brancato G, Agabiti N, et al. Respiratory symptoms and bronchial responsiveness are related to dietary salt intake and urinary responsiveness are related to dietary salt intake and urinary potassium
9 Demissie K, Ernst P. Is increased dietary salt intake a cause of increased airway responsiveness or a marker of an unhealthy life style? Respir Med 1994;88:79-81.

10 American Thoracic Society. Standardization of spirometry - 1987 update. Am Rev Respir Dis 1987;136:1285-98.

11 Kanner RE, Schenker MB, Munoz A, Speizer FE. Spirometry in children. Methodology for obtaining optima results for clinical and epidemiologic studies. Am Rev Respir Dis 1983;127:720-4.

12 Tsanakas JN, Milner RDG, Bannister OM, Boon WA. Free running asthma screening test. Arch Dis Child 1988;63: 261-5.

13 Eggleston PA, Rosenthal RR, Anderson SA, Anderson R Bierman W, Bleecker ER, et al. Guidelines for the methodology of exercise challenge testing of asthmatics. Study group on exercise challenge, bronchoprovocation committee, American Academy of Allergy. $\mathcal{F}$ Allergy Clin Immunol 1979;64:642-5.

14 Willett WC. Nutritional epidemiology. New York: Oxford University Press, 1990.

15 Pennington JAT, Young BE, Wilson DB, Johnson RD, Vanderveen JE. Mineral content of foods and total diets. The selected minerals in food surveys, 1982 to 1984 . $\mathscr{f}$ Am Diet Assoc 1986;86:876-91.

16 Caggiula AW, Wing RR, Nowalk MP, Milas NC, Lee S, Langford $\mathrm{H}$. The measurement of sodium and potassium intake. Am $₹$ Clin Nutr 1985;42:391-8.

17 Statistics Canada. Standard division: Standard Occupational Classification (1980). Catalogue 12-565E.

1981 socioeconomic index for occupations in Canada. Can Rev Sociol Anthropol 1987;24:465-88.

19 Yan K, Salome C, Woolcock AJ. Rapid method for measurement of bronchial responsiveness. Thorax 1983;38:760-5.

20 Kleinbaum DG, Kupper LL, Morgenstern H. Epidemiologic research: principles and quantitative methods. Lifetime Learning 1982:419-46.

21 O'Connor G, Sparrow D, Taylor D, Segal M, Weiss S, Eleuteri D. Analysis of dose-response curves to methacholine. An approach suitable for population studies. $\mathrm{Am}$ Rev Respir Dis 1987;136:1417-23.

22 Abramson MJ, Saunders NA, Hensley MJ. Analysis of bronchial reactivity in epidemiological studies. Thorax bronchial reactivit

23 Peat JK, Salome CM, Berry G, Woolcock AJ. Relation of dose-response slope to respiratory symptoms and lung function in a population study of adults living in Busselton, Western Australia. Am Rev Respir Dis 1992;146:860-5.

24 SAS Institute Inc. Statistical Analysis System. Version 6 . Cary, NC: SAS Institute Inc, 1989.

25 Mauritsen B. EGRET: Epidemiological graphics, estimation and testing package. Seattle, Washington: SERC, 1987.

26 Bhagat RG, Grunstein MM. Comparison of responsiveness to methacholine, histamine, and exercise in subgroups of
asthmatic children. Am Rev Respir Dis 1984;129:221-4.

27 Kerr GR, Amante P, Decker M, Callen PW. Ethnic pattern of salt purchase in Houston, Texas. Am $\mathcal{F}$ Epidemiol 1982; 115:906-16.

28 Forastiere F, Agabete N, Corbo GM, Pistelli R, Dell'Orco $\mathrm{U}$, Ciappi G, et al. Passive smoking as a determinant of bronchial responsiveness in children. Am Rev Respir Cri Care Med 1994;149:365-70.

29 Falliers CJ, Cardosa R, Bane H, Coffey R, Middleton E. Discordant allergic manifestations in monozygotic twins, genetic identity versus clinical physiologic and biochemical differences. $\mathcal{F}$ Allergy 1971;47:209-19.

30 Souhrada JF, Souhrada M. Significance of the sodium pump for airway smooth muscle. Eur $f$ Respir Dis 1983, 128(Suppl):196-205.

31 Nath P, Joshi AP, Agrawal KP. Biochemical correlates of airway hyperreactivity in guinea-pigs, role of lysophosphatidyl choline. F Allergy Clin Immunol 1983;72. phosphatid

32 Uvnas $\mathrm{B}$, Aborg $\mathrm{CH}$, Lyssarides L, Danielsson LG. Intracellular ion exchange between cytoplasmic potassium and cellular ion exchange between cytoplasmic potassium and
granule histamine, an integrated link in the histamine granule histamine, an integrated link in the histamine
release machinery of mast cells. Acta Physiol Scand 1989;
136:309-20.

33 Kakuta Y, Okayama H, Aikawa T, Kanno T, Ohyama T, Sasaki $\mathrm{H}$, et al. $\mathrm{K}$ channels of human alveolar macrophages. $\mathcal{F}$ Allergy Clin Immunol 1988;81:460-8.

34 Black JL, Barnes PJ. Potassium channels and airway function: new therapeutic prospects. Thorax 1990;45:213-8.

35 Haas F, Levine N, Axen K, Perelman SI, Pineda H, Haas A. Changes in serum $\mathrm{K}^{+}$in healthy and in asthmatic subjects during exercise. Am Rev Respir Dis 1988;137: 833-6.

36 Clough JB, Hutchinson SA, Williams JD, Holgate ST. Airway response to exercise and methacholine in children Airway response to exercise and methacholine in children
with respiratory symptoms. Arch Dis Child 1991;66:57983 . 